\title{
A review of Greenhouse Climate Control and Automation Systems in Tropical Regions.
}

\begin{abstract}
Design and development of automation system for a tropical greenhouse involves different phases, including studying of environmental factors and crop responses, control algorithm, instrumentation and software/hardware interface. In contrast to cold arid climates, a tropical greenhouse is not to provide a warm and humid environment for crop, but to create an ideal condition in which plants can be protected against heavy rainfalls, direct sun radiation, disease, insects and birds. High relative humidity and ambient temperature climate in a tropical greenhouse creates a complicated dynamic system that is influenced by changes of external conditions, making it a challenging environmental control task. This paper reviews and addresses issues involved in the design procedure of automation control system in tropical greenhouses.
\end{abstract}

Keyword: tropical greenhouse, automation, climate control, temperature, relative humidity, vapor pressure deficit. 